\title{
2016 CIPHI Award Winners
}

The 2016 CIPHI Awards were handed out during the most recent National AGM in September in Edmonton. Congratulations to all the winners!

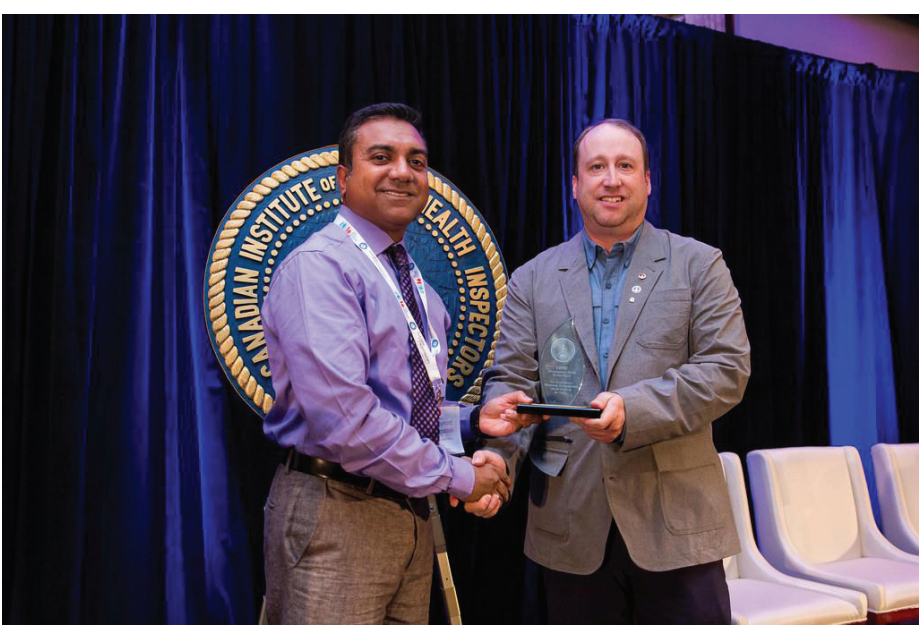

Raymond Ramdayal (left), ON Branch President-Elect, accepting the Environmental Health Review Award from Sean O'Toole (right), NEC Awards Committee Co-Chair, on behalf of Aptie Sookoo of ON Branch.

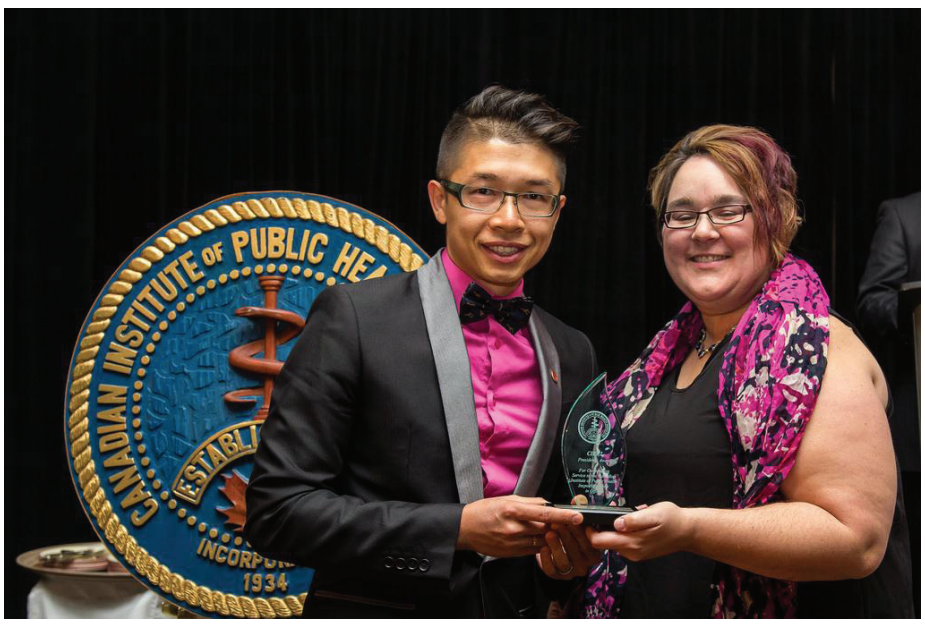

Gary Tam (left) received the 2016 Presidents Award recipient from Kari Engele-Carter (right), NEC Awards Committee CoChair \& SK Branch President.

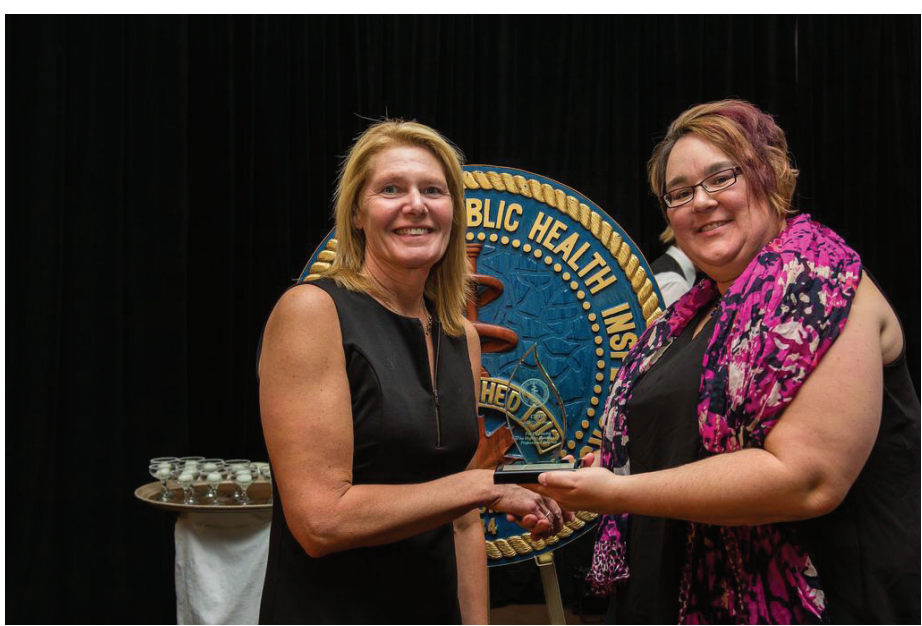

Janice Gammie (left), NS Branch member, accepted the Alex Cross Award on behalf of James McCorry from Kari EngeleCarter (right).

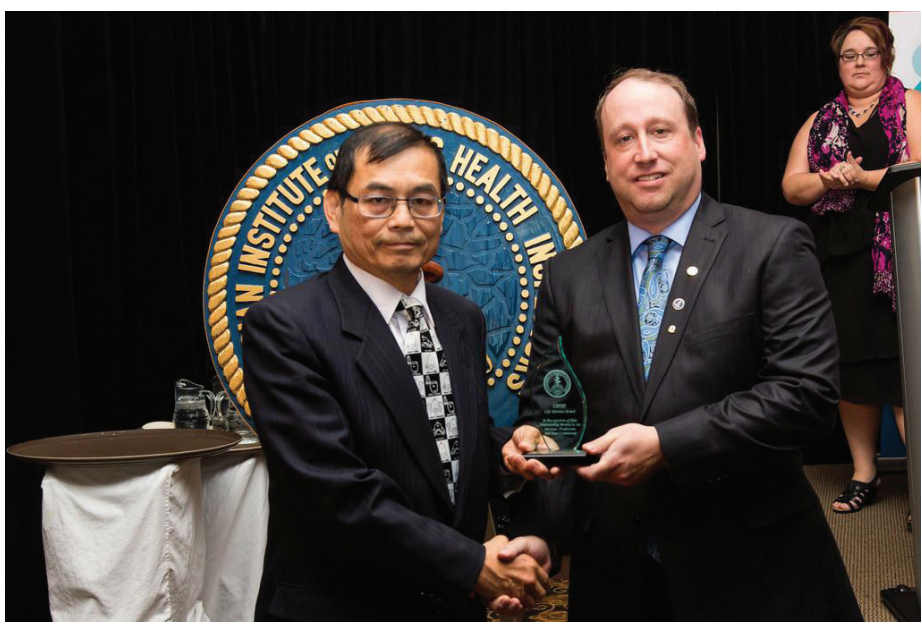

Nelson Fok, Alberta Member (left), receiving the 2016 Life Member Award from Sean O’Toole (right). 


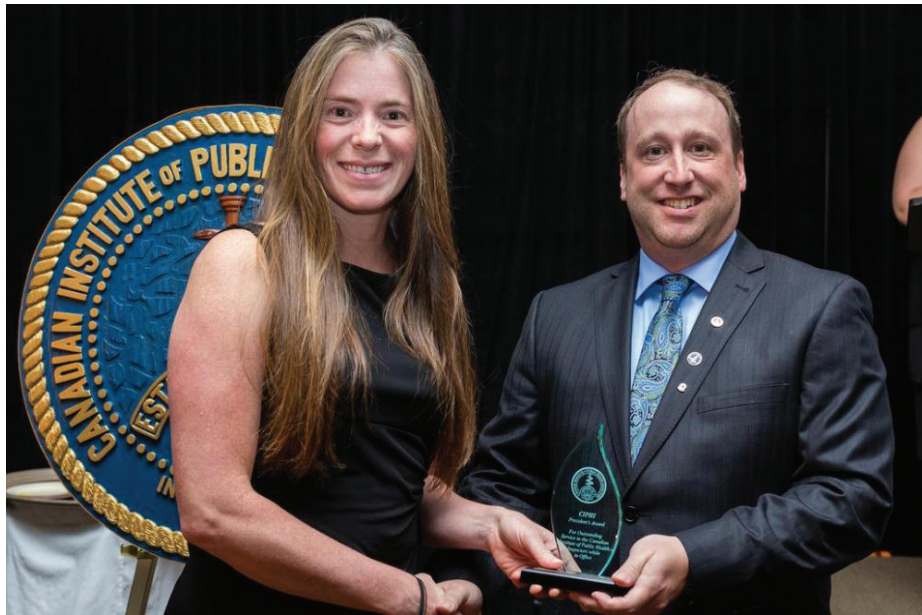

Nina van der Pluijm (left), the 2016 Presidents Award recipient with presenter Sean O'Toole (right).

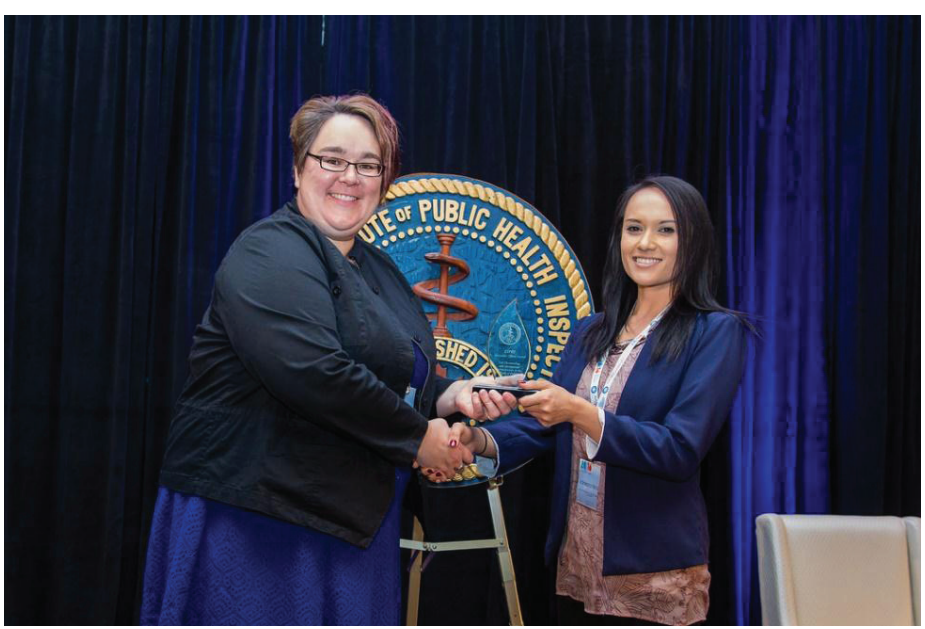

Kari Engle-Carter, NEC Award Committee Co-chair and SK President (left) with Vanessa Nickelo who is accepting the 2016 Alexander Officer Award on behalf of the Nova Scotia Department of Health and Wellness.

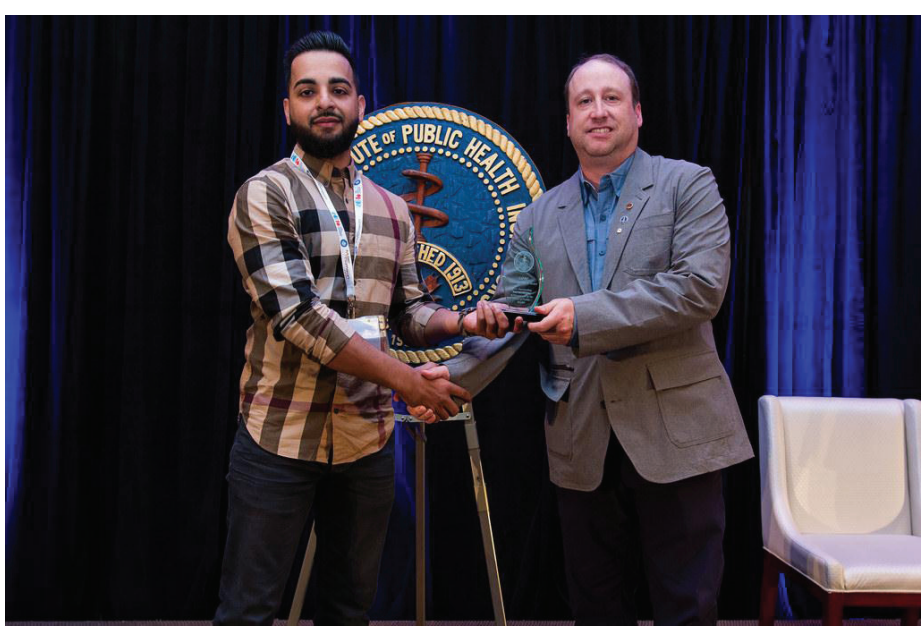

Sean O'Toole (right) with Ali Ran (left), VP CIPHI MB Branch who is accepting the 2016 Alexander Officer Award on behalf of the Prairie Mountain Interagency Hoarding Coalition.

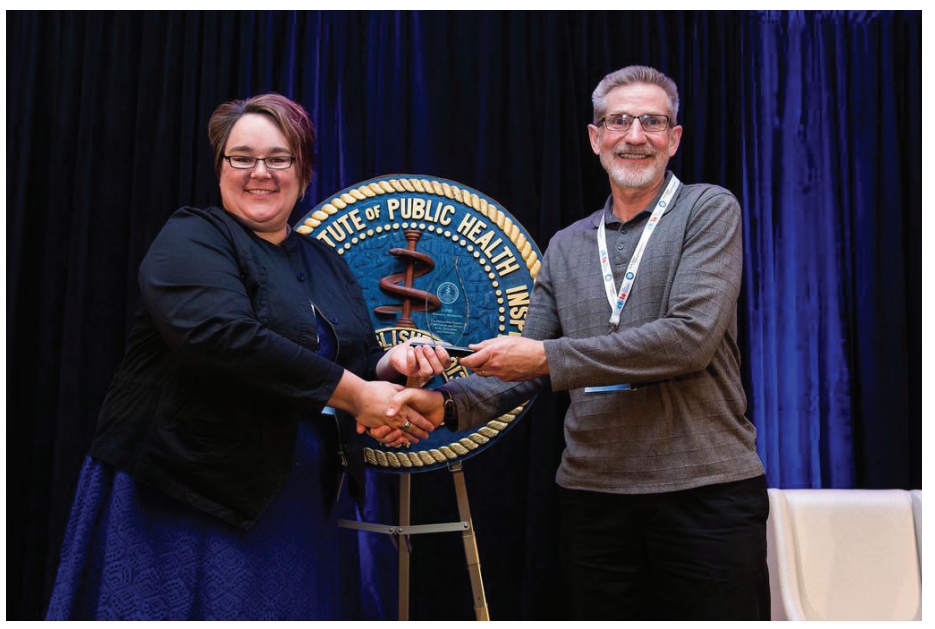

Kari Engle-Carter, NEC Award Committee Co-chair and SK President (left), presented Warren Kindzierski (right) with the 2015 Honorary Member Award.

Congratulations to the 50-year membership award Recipients Norbert (Bert) Bernard and Dean Sergeant of Manitoba Branch. Awards were to be presented by Manitoba Branch. 